ISSN:2528-9527

E-ISSN : 2528-9535

YIl Year: 8

Cilt Volume: 9

Sayı Issue : 16

\title{
Kırsal Turizm Bağlamında Muğla'da Dağ Kültü, Eren Kültü Kapsamındaki Gelenekler ve Şenlikler
}

\author{
DOI: $10.26466 / o p u s .486024$
}

Mehmet Naci Önal ${ }^{*}$ - Taner Dalgin ${ }^{* *}$ - Levent Karadağ

* Prof. Dr., Muğla Sıtkı Koçman Üniversitesi, Edebiyat Fakültesi, Muğla / Türkiye

E-posta: onaci@mu.edu.tr ORCID: 0000-0002-2397-0697

** Öğr. Gör. Dr., Muğla Sitkı Koçman Üniversitesi, Muğla Meslek Yüksekokulu, Muğla / Türkiye

E-posta: tanerdalgin@mu.edu.tr

ORCID: 0000-0002-7645-1989

*** Dr. Öğr. Üyesi, Muğla Sıtkı Koçman Üniversitesi, Datça Kazım Yılmaz MYO, Muğla/Türkiye

E-posta: leventk@mu.edu.tr

ORCID: 0000-0002-0932-8315

\section{Öz}

İnsanların olağanın dışına çıkma, yeni şeyler keşfetme, farklı olanı görme ve deneyimleme yönündeki istekleri alternatif turizm türlerini sürükleyen en önemli itici güç durumundadır. Özellikle kültür ve yerel yaşantı konusunda giderek artan merak, son dönemde özellikle aktif hayat tarzına sahip turist kitlesini turizm faaliyetlerine yönelten önemli bir unsur olarak ön plana çıkmaya başlamıştır. Bu çalışmada, hem potansiyel turistler, hem turizm girişimcileri için potansiyel bir çekicilik unsuru olduğu düşünülen Muğla Çiçek baba dağına ilişkin dă̆ ve eren kültü detaylı şekilde anlatılmaya çalışılmış ve dağ kültü, eren kültü çerçevesinde oluşturulmuş gelenekler ve şenlikler incelenmiştir. Araştırma, kültürel bir çekicilik unsuru olarak Muğla'da dă̆g, eren kültü kapsamındaki yerel yaşantının, bir sürdürülebilir turistik ürün olarak nasıl kullanılabileceğini ortaya koymayı amaçlamaktadır. Kültürel bir çekicilik olarak Muğla'da dă̆ ve eren kültünün tanıtılması ve turizme kazandırılması inanç turizmine, kırsal turizme ve kültür turizmine merak duyan geniş bir potansiyel turist kitlesinin bölgeye çekilmesini sağlayacaktır. Araştırma sonuçlarına bakıldığında, bölgede yaşayan yerel halkın, dă̆ ve eren kültü ile ilgili inançlarına yönelik gerçekleştirdikleri faaliyetlerin ve yaşam tarzlarının, turizm açısından önemli bir çekicilik unsuru oluşturduğu görülmüştür. Ayrıca, şenliklere katılımın yoğunlaşmasının yerel halk için, ürettikleri tarımsal ve hayvansal ürünleri daha kolay şekilde ekonomik değere dönüştürmek açısından katkı yaratacă̆ı düşünülmektedir.

Anahtar Kelimeler: Kırsal turizm, Kültür Turizmi, İnanç Turizmi, Dă̆ Kültü, Eren Kültü.

OPUS (c) Uluslararası Toplum Araştırmaları Dergisi-International Journal of Society Researches ISSN:2528-9527 E-ISSN : 2528-9535

http://opusjournal.net 


\title{
Folkways and Festivals About Mountain and Saint Cult That One of Rural Attractiveness in Muğla
}

\begin{abstract}
Some wishing of people like having an experience out of ordinary, discovering different things and places are most important impetus that develop alternative tourism types. Specially, ever increasing interest about culture and local lifestyle begin to attract people that have proactive lifestyle to tourism activities, recently. In this study, we mention mountain and saint cult about Çiçek Baba Mountain that we think, it is very important for potential tourists and tourism entrepreneurs both, in Muğla region. Also, we investigate folkways and festivals about mountain and saint cult in Muğla. The aim of study is suggest local life about mountain and saint cult in Muğla as sustainable cultural tourism attraction. Promotion of mountain and saint cult about Çiçek Baba Mountain as cultural attraction contribute to attract wide range of potential tourist that interested in rural tourism, religious tourism and culture tourism. It is important to bring mountain and saint cult about Çiçek Baba Mountain in tourism for these reasons. Consequently, when we evaluate the research results, we can say folkways and festivals about mountain and saint cult belief of local people in Muğla is important and authentic tourism attraction for this region. In addition, broad participation in this festival may contribute to increase economic value of agricultural and animal products that produce by local people.
\end{abstract}

Keywords: Rural Tourism, Culture Tourism, Religious Tourism, Mountain Cult, Saint Cult

OPUS (c) Uluslararası Toplum Araştırmaları Dergisi-International Journal of Society Researches ISSN:2528-9527 E-ISSN : 2528-9535

http://opusjournal.net 


\section{Giriş}

İnsanoğlunun yaradılışında var olan görme ve öğrenme isteği, ekonomik, kültürel etkenlerin de etkisiyle eski çağlardan bu yana insanları seyahat etmeye yönlendirmiştir. Turizme katılan ziyaretçilerin, olağanın dışına çıkma, yeni şeyler keşfetme, farklı olanı görme ve deneyimleme yönündeki istekleri geçmişten bugüne alternatif turizm türlerini sürükleyen en önemli itici güç olmuştur. Son zamanlarda kültür ve yerel yaşantı konusunda giderek artan merak, özellikle aktif hayat tarzına sahip turist kitlesini turizm faaliyetlerine yönelten önemli bir unsur olarak ön plana çıkmaya başlamıştır. Bir kırsal turizm çekiciliği olarak değerlendirilebilecek olan kültür ve yerel yaşantı, önemli bir turistik ürün olarak hem potansiyel ziyaretçilerin, hem de yenilikçi turistik ürünler ortaya koymayı amaçlayan turizm girişimcilerinin ilgisini çekmektedir. Bu ilgi yeni turizm etkinliklerini ve alanlarını ortaya çıkarmayı ve yaygınlaştırmayı amaçlayan çalışmaların önemini arttırmaktadır.

$\mathrm{Bu}$ çalışmada, hem potansiyel turistler, hem turizm girişimcileri için potansiyel bir çekicilik unsuru olduğu düşünülen Muğla Çiçek dağına ilişkin dağ ve eren kültü detaylı şekilde anlatılmaya çalışılmış ve dağ kültü, eren kültü çerçevesinde oluşturulmuş gelenekler ve şenlikler incelenmiştir. Araştırma kültürel bir çekicilik unsuru olarak Muğla'da dağ, eren kültü kapsamındaki yerel yaşantının bir sürdürülebilir turistik ürün olarak nasıl kullanılabileceğini ortaya koymayı amaçlamaktadır. Ayrıca, söz konusu turistik çekiciliğin, özellikle kültür ve yerel yaşantıya ilgi duyan turist kitlesine nasıl duyurulabileceği konusunda çözüm önerilerinin geliştirilmesi bu çalışmada hedeflemektedir. Öncelikle kırsal turizm kavramı ve etkinlikleri anlatılarak, dağ ve eren kültü kırsal turizm ve kültür turizmi içerisinde konumlandırılmaya çalışılmıştır. Daha sonra Muğla bölgesindeki dağ ve eren kültü kapsamındaki inanışlar anlatılmış, bu kapsamdaki yerel halkın geleneklerinden ve şenliklerinden bahsedilmiştir. En son olarak kültürel anlamdaki bu çekiciliklerin kırsal turizm açısından oluşturabileceği potansiyel değer ele alınmıştır. 


\section{Kırsal Turizm Kavramı Ve Kırsal Turizmin Kapsamı}

Kırsal turizm, özellikle temel geçim kaynağı tarım ve hayvancılık faaliyetleri olan yörelerde, bölgesel kalkınmaya katkı sağlamak amacıyla tarım ve hayvancılık faaliyetlerin yanı sıra, turizm faaliyetlerinin sinırlı olarak geliştirilmesi ve sürdürülmesi üzerine odaklanan bir alternatif turizm çeşididir. Kırsal turizm, turistlerin mekan içinde yoğunlaşması sebebiyle ortaya çıkan ekonomik, sosyal ve psikolojik sorunların çözümünde önem arz etmektedir. Kirsal yörelerin dinlendirici atmosferinden yararlanmaya amaçlayan, genellikle aktif bir hayat tarzına sahip turist kitlesi, hem kırsal alanlarda benzersiz bir tatil deneyimi yaşamakta, hem de gelir düzeyi diğer sektörlere göre düşük olan tarım üreticisine ek bir gelir sağlamaktadır (Olalı ve Timur, 1988, s.400).

Kırsal turizmle ilgili tanımlara baktığımızda ilgili uluslararası kuruluşlar ve araştırmacılar tarafından birçok farklı tanım yapıldı̆̆ı görülmektedir. Avrupa Birliği tarafından yapılan çalışmalarda kırsal turizmin "Tarımsal ya da yerel değerlerle iç içe bulunarak hoşça zaman geçirmek amacında olan turistlere, beklentileri doğrultusunda konaklama, yiyecek, içecek ve diğer hizmetleri veren küçük ölçekli işletmelerin yer aldığı küçük yerleşimlerde gerçekleştirilen faaliyetler bütünü" olarak ifade edildiği görülmektedir (EC, 1999, s. 151). Kitle turizmi ile ilgili olumsuzlukların daha çok farkına varılması ve alternatif turizme olan talebin artması ile birlikte, kırsal bölgelerin doğal güzelliklerini görmek, farklı kültürlerden insanlarla bir araya gelmek, kırsal yöreye özgü faaliyetlere katılmak, doğa ve çevre ile bütünleşmek amacıyla turizm faaliyetlerine katılan insanların sayısı önemli bir artış göstermiştir (Gölbaş ve Atak, 2016, s.1216). Talep yönlü bu artış, yenilikçi girişimlerin kırsal turizme yönelik farklı turistik ürünleri arzıyla daha da hız kazanmıştır.

Kırsal turizmi basit olarak kırsal alanlara yapilan seyahat olarak da tanımlamak mümkündür. Fakat kırsal turizmi ortaya çıkaran unsurlara ve kırsal turizme yönelik beklentilere odaklanmak kırsal turizmi ele almakta daha doğru bir yaklaşım olacaktır. Kırsal turizm, gündelik yaşamın monotonluğundan sıkılmış, çevreye duyarlı turistik tüketicilerin doğayla bütünleşme isteğiyle hareket ettiği, çevresel tahribatın ve gürültü kirliliğinin en az düzeye indirilmeye çalışıldığı, yerel kültüre ait etkin- 
likleri deneyimleme ve gözlemleme odaklı turizm faaliyetlerini kapsamaktadır (Civelek vd., 2013, s.3).

$\mathrm{Bu}$ tanımlardan hareketle kırsal turizmi "kırsal yerleşimlerde yaşayan insanlarla iç içe gerçekleştirilen ve çoğu zaman yerel halkın kültürel özellikleri de dahil olmak üzere, birçok kırsal çekiciliğin turistik ürün olarak değerlendirilebileceği, sürdürülebilirlik ilkelerine uygun olarak gerçekleştirilen bir alternatif turizm şekli" olarak tanımlayabiliriz.

Kirsal turizmin temelinde yer alması gereken en önemli konu, doğal dokunun ve kültürel yapının bozulmadan bir çekicilik unsuru olarak sunulabilmesi ve kırsal turizm uygulamalarında da bu çekicilik unsurunun korunabilmesidir. Yerli ve yabancı turistin kırsal turizmle ilgili aktivitelere, kırsal çekiciliklere ve yerel yaşantıya zarar vermeden katılımının sağlanabilmesi kırsal turizm açısından bir zorunluluktur. Bunun sağlanabilmesi için kırsal alanları turistik faaliyetlere açarken, öncelikle bu bölgelerin taşıma kapasitelerine dikkate alan bir kırsal turizm planlaması yapılması gerekir. Kırsal turizm çalışmalarında koruma kullanma ilkelerine uygun hareket edilmesi oldukça önemlidir. Büyük kitlelerin plansız şekilde, kırsal değerleri çok fazla gözetmeksizin, kırsal turizme yönlendirilmesi, kırsal turizmin genel felsefesine aykırıdır. Bu nedenle kırsal kaynakları en az yıpratacak ve kırsal kültürü en az asimile edecek şekilde ve kapasitelerde kırsal turizm faaliyetlerin yürütülmesi son derece önemlidir (Çeken vd., 2012).

Kirsal turizmin kapsaminı daha net anlayabilmek amaciyla, bu turizm türünün içeriğini oluşturan ürün bileşenlerini ve faaliyetleri belirlemek oldukça önemlidir. Kırsal turizm sadece kırsal alanların gezilip görülmesini içeren bir turizm türü değildir. Kırsal turizmin pasif katılımdan daha çok aktif katılıma uygun yapısı, kırsal turizm kapsamındaki aktivitelerin çeşitliliğini de arttırmaktadır. Doğa gezileri, alışveriş, kayak, macera aktiviteleri, rafting, yürüyüş, tırmanış, termal turizm, avcılık, balıkçılık, kuş gözlemciliği (ornitoloji), yamaç paraşütü, dağcılık, kanoculuk, sanat, tarih ve etnik yapıyla ilgili faaliyetler kırsal turizmin kapsamına dahil edilebilecek yada onunla bütünleştirilebilecek aktivitelerden ilk akla gelenlerdir (Bramwell and Lane, 1994; Soykan, 2006).

Bunun yanında yöresel yemeklerin, el sanatlarının, gelenek, göreneklerin yaşatılmasını sağlamak ve bunları tanıtmak için yapılan faaliyetleri de kırsal turizm içerisinde değerlendirmek mümkündür. Kırsal turizmi 
sadece kırsal bölgelerdeki fiziki çekiciliklerle ve gerçekleştirilecek faaliyetlerle sınırlı tutmak yeterince kapsamlı bir yaklaşım olmayacaktır. Bütün bu çekiciliklerin yanında, kırsal bölgede yaşayan insanların oluşturduğu ortak kültürü, kırsal turizm için en önemli bileşen olarak ele almak doğru olacaktır. Bu noktada, yerel halka ait kültürün en önemli yansımaları olan şenlikler, panayırlar, kutlamalar, dini törenler, düğünler, bayramlar ve belki de cenazeler, kırsal turizm için en önemli çekicilikler olarak değerlendirilebilir. Bu çalışmada daha çok yerel halkın dağ ve eren kültü inanışının bir sonucu olarak ortaya çıkan şenlikler ve kutlamalar üzerinde durulmuştur. Yerel halkın dağ ve eren kültüne ilişkin bu gelenek ve şenlikler, kırsal turizm açısından otantik ve farklı bir değere sahiptir. Bu değerin insanlar tarafından anlaşılması ve turistik açıdan bir çekicilik oluşturması ise ancak, dağ ve eren kültü ile ilgili gelenek ve şenliklerin altında yatan hikayelerin bilinmesi ile mümkündür.

\section{Bir Kırsal Turizm Çekiciliği Olarak Muğla'da Dağ, Eren Kültüyle İlgi- li Gelenekler Ve Şenlikler}

Toplumların yaşam biçimlerini belirleyen çeşitli öyküler, efsaneler, kuşaktan kuşağa, dilden dile aktarılan ve kültürel zenginliğin temelini oluşturan somut olmayan kültürel miras, özellikle kırsal hayat tarzının sürdürüldügü bölgelerde önemli bir turizm çekiciliğini oluşturmaktadır. Şenlikler ve kutlamalar, toplumların kültürlerini ve kendine özgü değerlerini en yoğun şekilde yansıttıkları etkinlikler olarak dikkat çekmektedir. Bu etkinlikler için yöreye gelen farklı kültürlerden turistler, hem yerel kültürü gözlemlemeyi, hem de yerel halkla birlikte ortak bir deneyim yaşamayı hedeflemektedir. Bu çalışmada kırsal hayat tarzına, dağ ve eren kültüne merak duyan potansiyel turistlerin ilgisini çekebilecek bir çekicilik olarak çiçek baba dağ ve eren kültünden bahsedilmiş ve bu doğrultuda yerel halkın inanışları ve kutlamaları anlatılmıştır.

Dünyanın ve Türkiye'nin birçok farklı bölgesinde dağlarla ilgili inanışların ve bunlara bağlı ritüellerin var olduğu görülmektedir. Dağların, genellikle civarında yaşayan yöre halkı tarafından kutsal kabul edildiği ve onlar için dünyanın merkezi olma özelliği taşıdığı söylenebilir. Muğla ilinde ise, dağlarla ilgili inanışlar, eren kültü ile iç içe girerek varlığını sürdürmüş ve günümüze ulaşmıştır. Dağ kültü ve eren kültü çerçeve- 
sinde oluşturulmuş geleneklerden Köyceğiz sinırlarında yer alan Sandraz Dağı ve Ağla köyü ereni ile ilgili olanlar ve Çiçek Baba doruğundaki Çiçek Baba ile ilgili olanlar günümüzde de bütün canlılığıyla devam etmektedir.

$\mathrm{Bu}$ geleneklerden biri olan eren şenlikleri, Muğla ili Köyceğiz ilçesi sınırları içinde yer alan Gölgeli Dağlarının devamı olan Sandıraz Dağı'nda gerçekleşmektedir. Eren şenlikleri hem dağın batısında yer alan Ağla köyünde, hem de Sandıraz dağının zirvesinde birbirine yakın farklı tarihlerde yapılmaktadır. Ağla köyünde gerçekleşen şenlikler "Mahya" (halk arasında maya) olarak anılmakta ve şenliğin gerçekleştiği güne "eren günü" adı verilmektedir. Mahya kapsamında her yıl ağustos ayının ikinci perşembesi Ağla (diğer adı Yayla) köyünde bir araya gelinerek kutlamalar yapılmaktadır. Yılladır süregelen bir alışkanlıkla çevre köy, kasaba ve şehirlerde yaşayan herkes bu özel güne hazırlığını yaparak, şenlik zamanı geldiğinde, önceden sözleşmiş gibi eren ziyaretine gelmektedir. Şenlik sırasında adak kurbanları kesilmekte, kurban eti, hem kesenler tarafından yenilmekte, hem de şenlikteki misafirlere ikram edilmektedir. Akşama kadar devam eden şenlik sırasında ziyaretçiler çeşitli dileklerde bulunurlar ve dua ederler (Karaağaç, 1977). Ağla'daki türbe "eren kavak" adı verilen kutlu bir ağaçtır. Burada bir erene ait mezar olmasa da, erenin hikmeti sayılan kutlu bir ağaç bulunmaktadır. Çiçek Baba hakkında halk arasında anlatılan menkıbede bu kutlu ağaç önemli bir yer tutmaktadır. Erenin duası sonunda bu ağacın eğildiği ve gölge yaptığı rivayet edilmektedir. Ayrıca, Ağla köyünün adını efsanede geçen diğer bir olaydan aldığına inanılmaktadır. Çiçek Baba asasını yere vurur "ağla" der ve yerden su çıkar. Bunu üzerine köyün adı "Ağla" olarak kalır (Başlaran 1999; Belgrat 1999).

Muğla'da en canlı şekilde ve en geniş katılımla gerçekleşen eren ziyaretleri, Batı Torosların son uzantısı olan Gölgeli Dağlarının Sandıraz doruğunda yapılan Çiçek Baba ziyaretleridir. Muğla'nın Köyceğiz ilçesi ile Denizli'ye bağlı Tavas ilçesinin Beyağaç beldesi arasında kalan Sandıraz dağının zirvesinde halk arasında Çiçek Baba olarak bilinen erenin mezarı bulunmaktadır. Mezarın boyu otuz dört metre yirmi santim uzunluğunda, eni üç metre on santim genişliğindedir. Mezarın baş tarafı kıbleye doğru uzanmaktadır. Mezarın kenarlarında dokuz adet büyükçe taş yer almaktadır. Göğüsleri hizasından kıbleye doğru yöneldikleri göz önüne 
alındığında dokuz mezarın olma ihtimali düşünülebilir. Aksi halde bir erenin otuz metreden daha uzun olan ve kıbleye uymayan yönü ile karşılaşılır.

Çiçek Baba ziyaretlerinin ve şenliklerin ne zamandan beri yapıldığı bilinmemektedir. Şenliğe gelenler, babalarının ve dedelerinin bu şenliklere katıldıklarını, kendilerinin de çocukluk yıllarından itibaren bu geleneği devam ettirdiklerini belirtmektedir. Çiçek Baba için yapılan şenlikler her yıl ağustos ayının son perşembesinde gerçekleştirilmekte ve bu güne "Eren Günü" denilmektedir. Ziyaretçiler, birbirleriyle haberleşmeksizin ve şenliğe özel hazırlıklar yaparak gelmektedir.

1994 yılından itibaren Denizli'nin Beyağaç Belediyesi "Geleneksel Eren Günü, Kartal Gölü Yörük Şenlikleri" adı altında şenlikler düzenlemektedir. Denizli ili, Tavas ilçesi ve Beyağaç beldesi civarından gelen ziyaretçilerin kimi bir hafta, kimi üç gün, kimi bir gün öncesinden Sand1raz Dağı'na, erene yaya olarak yaklaşık bir saatlik mesafede bulunan Kartal Gölü'ne gelirler. Kartal Gölü'nde çadır ve yatak yerleri hazırlayarak, eren yürüyüşüne kadar konaklarlar. Köyceğiz tarafından gelen ziyaretçilerin ise bir kısmı şenliklerin düzenlendiği günden bir gün önce dağa çıkarlar. Ziyaretçiler çarşamba gecesini erenin etrafında geçirir, diğer çadırlara ve obalara ziyaretler yaparlar. Ağustos ayının son perşembesinde yapılan kutlamalar şenliğin odak noktasını oluşturmaktadır. Perşembe günü Beyağaç tarafından gelen ziyaretçiler, şafak vakti Kartal Gölü'nden hep birlikte erenin bulunduğu zirveye yürürler. Bu yürüyüşe "eren yürüyüşü" adı verilmektedir. Çiçek Baba'nın mezarı etrafında hem Denizli tarafından, hem Köyceğiz tarafından, gelen ziyaretçiler bir araya gelmekte ve mezarın etrafında üç kez dönerek bir takım inanç ritüellerini yerine getirmektedirler. Kimi ziyaretçiler adaklarla (kurban edilecek oğlak ve keçilerle) birlikte, kimi ziyaretçiler kucaklarındaki bebeklerle mezarın etrafında dönmekte ve bu esnada dua etmektedirler. Ziyaretçiler dua ve dileklerinin kabul olacağına ve eren ziyaretini yaptıkları yıl bütün işlerinin rast gideceğine gönülden inanırlar.

Çiçek Baba ziyaretleri çeşitli yerlerden gelenlerle birlikte geniş katılımlı bir şenliğe dönüşmüştür. Kartal Gölü'nden gelenler adak kurbanlarını da beraberinde getirmektedir. Kurban en az üç kez Çiçek Baba mezarının etrafında dolaştırıldıktan sonra kesilmekte ve kanı toprağa akıtılmaktadır. Yaklaşık üç dört metre genişliğinde ocaklar kurularak, kesi- 
len ve sırıklara geçirilen kurban, bu ocaklarda çevrilerek altı yedi saat pişirilmekte, etin kokusu ile dumanı havaya savrulmaktadır. Adak olan bu kurbanlar, tanıdık tanımadık sofralara davet edilen bütün ziyaretçiler tarafından afiyetle yenir. Erenin etrafında isteyenler gün boyunca tek veya toplu olarak üç kere dönmeye devam eder ve dileklerde bulunur. Yerel halkın eren ziyaretinde gerçekleştirdiği birçok farklı inanış vardır.

Yerel halkın bir kısmı, erenin mezarından toprak alarak, bu toprağ 1 evin bir köşesinde, ambarda, tarlada veya arabasının bir köşesinde, hayır ve bereket getirmesi dileğiyle saklamaktadır. Bazense, alınan toprak parçası, askere gidecek gençlerin boyunlarına astıkları muskalara koyulur. Bunun sebebi "toprak çeker" şeklindeki inanıştır. Askere giden gencin erenin de himmetiyle salimen geri döneceğine inanılmaktadır. Kimi ziyaretçiler ise, çocuk çorabı, mendil veya herhangi bir eşyasını, mezarın içinde bulunan küçük taşların altına dua ve dileklerle bırakır.

Halk arasında Çiçek Baba dağı ismiyle bilinen Sandıraz Dağı ile ilgili söylenegelen birçok farklı efsane vardır. Çiçek Baba ismi, kimi ziyaretçilere göre, dağa ismini veren eren çiçek hastalığına yakalandığı için, kimilerine göre ise, erenin çiçekleri çok sevmesi sebebiyle dağa verilmiştir. Halk arasında genel olarak anlatılan Efsaneye göre, Çiçek Baba Dağı ile karşısındaki Atkuyruksallamaz Dağı kavgaya tutuşurlar. Birbirlerine top atarlar. Atkuyruksal1amaz Dağı topu Sandıraz Dağına ulaştıramaz. Oysa Sandıraz dağı attığ toplarla Atkuyruksallamaz Dağının tepesini uçurur. Bunun üzerine Atkuyruksallamaz Dağı sen büyüksün anlamında, "Sen dırazsın!"der. Daha sonra dağın adı "Sandıraz" olarak kalmıştır (Önal, 2003; Önal, 2013).

\section{Sonuç ve Değerlendirme}

Kültürel bir çekicilik olarak Muğla' da dağ ve eren kültünün tanıtılması ve turizme kazandırılması inanç turizmine, kırsal turizme ve kültür turizmine merak duyan geniş bir potansiyel turist kitlesinin bölgeye çekilmesini sağlayacaktır. Bölgede yaşayan yerel halkın dağ ve eren kültü ile ilgili inançlarına yönelik gerçekleştirdikleri faaliyetler ve yaşam tarzları inanç turizmi açısından önemli bir çekicilik unsurudur. Benzer dağ ve eren kültü kapsamındaki inanışlar Muğla genelinde birçok yüksek dağ ile ilgili var olsa da, bu inanışların en kapsamlısı ve yerel halk tarafından 
en çok katılım sağlanılanı Çiçek Baba Dağı ile ilgili olanlardır. Bu çalışmada Çiçek Baba Dağı ile ilgili inanışlar kapsamındaki gelenekler ve şenlikler detaylı olarak anlatılmış ve bir turistik çekicilik olarak tanıtılmaya çalışılmıştır. Muğla ili özellikle deniz, güneş, kum üçgeninde önemli turistik destinasyonlara sahip olmakla birlikte, kültür turizmi, inanç turizmi ve kırsal turizm gibi alternatif turizm türleri kapsamında ilgi çekebilecek birçok değere sahiptir (Çeken vd., 2013).

Turistik anlamda bilinirliğe henüz sahip olmasa da, her geçen gün bu kapsamdaki şenliklere katılımın artması ve dünyada bu tür yerel aktif turizm uygulamalarına olan ilginin yoğunlaşması sebebiyle, Çiçek Baba Dağı önemli bir potansiyele sahiptir. Bu potansiyelin ortaya çıkarılması ancak, ciddi anlamda, bu geleneklerin ve şenliklerin bilinirliğini arttırmaya yönelik çalışmalar yapılmasıyla mümkündür. Bu noktada, yerel yönetimlere ve turizm konusunda çalışmalar yapan araştırmacılara önemli görevler düşmektedir. Özellikle şenlikler zamanında yapılan kutlamalara ve etkinliklere görsel ve yazılı medyada yer verilmesi, öncesinde ve sonrasında çeşitli haberlerin yayınlanması, bu etkinliklere olan ilgiliyi arttıracaktır. Çiçek Baba Dağı ile ilgili dağ ve eren kültü kapsamındaki şenliklerin medyada yer bulabilmesi, ancak yerel yönetimin girişimci yaklaşımlarıyla mümkün olacaktır.

Çiçek Baba Dağı ile ilgili eren şenliklerine katılımın artması için bazı düzenlemelerin ve girişimlerin de gerçekleştirilmesi gereklidir. Özellikle Sandraz dağı zirvesindeki şenliklere ulaşım, yolların bozuk olması ve karmaşıklığı sebebiyle oldukça zordur. Ulaşımı kolaylaştırmak için yol yapmak bölgenin doğal yapısına zarar vereceği için uygun değildir. Bunun yerine sadece şenlik zamanlarında dağ zirvesine ulaşım için traktörlerle düzenli seferler yapılması etkin bir çözüm olabilir. Ayrıca, dağ zirvesindeki şenlik alanına kendisi ulaşmak isteyenlerin ulaşımını kolaylaştırmak için tabelalar ile yönlendirmenin gerçekleştirilmesi gereklidir. Şenliklere katılımın arttırılmasına, seyahat acenteleri de, özellikle şenlikler zamanında turlar düzenleyerek katkı sağlayabilir. Bu noktada, sadece bu tür aktivitelere ilgi duyan ve zorluğunun farkında olan, çevreye karşı duyarlı bir turist kitlesinin katılımının sağlanması önemlidir. Tüketim odakll, çevreye zarar vermek konusunda hiçbir çekinceye sahip olmayan turist kitlesi, hem bölgenin doğal güzelliğini zarar verecek, hem de yerel halkın tepkisini çekecektir. 
En son olarak Çiçek Baba Dağı ile ilgili şenliklerin, yerel halk açısından yarattığ 1 ekonomik katkılara değinmek yerinde olacaktır. Şenlik zamanlarında yerel halk Dağ zirvesine giden yollar kenarında bölgede ürettikleri doğal sebze ve meyvelerini bahçeleri kenarında satmaya çalışmaktadır. Sattıkları ürünler organik ürünleri tüketmek isteğinde olan kişiler için önemli bir çekiciliktir. Şenliklere katılımın yoğunlaşması yerel halk için de ürettikleri tarımsal ve hayvansal ürünleri daha kolay şekilde ekonomik değere dönüştürmek açısından oldukça önemlidir.

Eren şenlikleri adakların kesildiği, herkesin inanışlarını özgürce sergilediği, paylaşmanın ve birlikte zaman geçirmenin en güzel şekilde yaşandığı, bugünün monoton günlük yaşantısından sıkılmış, doğal yaşama ve geçmişin samimiyetine özlem duyan turist kitlesi için, önemli bir turistik değer olarak ön plana çıkmaktadır. Eren şenlikleri kapsamındaki kültürel paylaşım, hem yerel halkın, hem de katılımcı turist kitlesinin deneyimlerini zenginleştirecektir. 


\title{
EXTENDED ABSTRACT
}

\section{Folkways and Festivals About Mountain and Saint Cult That One of Rural Attractiveness in Muğla}

\author{
Mehmet Naci Önal - Taner Dalgın - Levent Karada \\ Muğla Sitkı Koçman University
}

The desire to see and learn in the creation of mankind has led people to travel since ancient times with the effect of economic and cultural factors. In this context some wishing of people like having an experience out of ordinary, discovering different things and places are most important impetus that develop alternative tourism types. Specially, ever increasing interest about culture and local lifestyle begin to attract people that have proactive lifestyle to tourism activities, recently. On the other hand the intangible cultural heritage, which is the basis of cultural richness, is a significant tourist attraction in the regions where the rural lifestyle is maintained.Festivals and celebrations draw attention as the most intense reflections of the cultures and unique values of societies.

Tourists from different cultures who come to the region for these activities aim to observe the local culture and experience a common experience with the local people. In many different regions of the world and Turkey, there are beliefs about the mountains and rituals related to them. It can be said that the mountains are generally considered sacred by the local people who live in the vicinity and are the center of the world for them. In the province of Muğla, the beliefs about the mountains continued to exist with the cult of eren and survived to the present day. Those who are related to the Saint of Sandraz Mountain and Ağla village which are located within the borders of Köyceğiz and the ones related to Çiçek Baba at the peak of Çiçek Baba, continue with all their vivacity.One of these traditions, Saint festivities, takes place at the Sandiraz Mountain, which is the continuation of the Gölgeli Mountains within the borders of Köyceğiz district of Muğla province. 
In this study, we mention mountain and saint cult about Çiçek Baba Mountain that we think, it is very important for potential tourists and tourism entrepreneurs both, in Muğla region. Also, we investigate folkways and festivals about mountain and saint cult in Muğla. The aim of study is suggest local life about mountain and saint cult in Muğla as sustainable cultural tourism attraction. Promotion of mountain and saint cult about Çiçek Baba Mountain as cultural attraction contribute to attract wide range of potential tourist that interested in rural tourism, religious tourism and culture tourism. It is important to bring mountain and saint cult about Çiçek Baba Mountain in tourism for these reasons. Consequently, when we evaluate the research results, we can say folkways and festivals about mountain and saint cult belief of local people in Muğla is important and authentic tourism attraction for this region. In addition, broad participation in this festival may contribute to increase economic value of agricultural and animal products that produce by local people.

Introducing the cult of mountain and eren in Muğla as a cultural attraction, and gaining tourism, will attract a large potential tourist population interested in religious tourism, rural tourism and cultural tourism. The activities and lifestyles of the local people about their beliefs about the mountain and the cult of the region are an important element of faith tourism. Although the beliefs in the similar mountain and saint cult are related to many high mountains in Muğla, these are the most comprehensive of these beliefs and those related to Çiçek Baba Mountain which is the most attended by the local people. It has not been known since when the visits and the festivities were held. Those who came to the festival stated that their fathers and grandfathers attended these festivals and that they continued this tradition since their childhood. Çiçek Baba

Festivals are held every year on the last Thursday of August and this day is called as Saint Day. The visitors come without making contact with each other and making special preparations for the festival. Saint feasts stand out as an important tourist value for the mass of tourists who are attracted to the natural life and the sincerity of the past, where votive cuts are made free, everyone exhibits their beliefs freely, sharing and spending time together is the best way. The cultural exchange with- 
in the Eren festivities will enrich the experience of both the local population and the audience.

\section{Kaynakça/References}

Başlaran, M., (1952 Köyceğiz doğumlu, üniversite mezunu, muhasebeci, derleme tarihi 1999).

Belgrat, N. (1936 Beyobası beldesi/Köyceğiz doğumlu, ilkokul mezunu, çiftçi, derleme tarihi 1999).

Bramwell, B. ve Lane, B., (1994). Rural tourism and sustainable rural development. Proceedings from the Second International School of Rural Development, University College, Galway, Ireland, Channel View Books: London.

Çeken, H., Uçar, M. ve Dalgın, T., (2012). Kırsal turizmin gelişimi konusunda yerel halkın algıları: Fethiye yöresi örneği. Turizm ve Araştırma Dergisi, 1 (1), 4-28.

Çeken, H., Baldemir, E., Dalgın, T., Sop, S. A. ve Ercan, F., (2013). Muğla'da turizmin sorunlarıyla ilgili turizm sektörü yöneticilerinin algıları ve çözüm önerileri. Finans Politik \& Ekonomik Yorumlar, 50(576), 55-70.

Civelek, M., Dalgın, T., Çeken, H. ve Ekiztepe, B., (2013). Menemen yöresinde agro-turizm potansiyelinin değerlendirilmesi. Uluslararası Sosyal ve Ekonomik Bilimler Dergisi, 3(2), 01-07.

European Commission (EC) (1999). Towards quality rural tourism. Enterprise Directorate General, Brussels: Tourism Unit.

Gölbaş, A. ve Atak, O. (2016). Arkeolojik potansiyelin kırsal turizme kazandırılması: Ortaca örneği. Uluslararası Sosyal Araştırmalar Dergisi, 9(47), 1210-1222.

Karaağaç, G. (1997). Köyceğiz. İstanbul: Pengraf Reklam Hizmetleri.

Olalı, H. ve Timur, A. (1988). Turizm ekonomisi. İzmir: İnce Ofset MatbaaS1.

Önal, M. N. (2003). Dağ kültü, eren kültü ve şenliklerinin Muğla'daki yansımaları. Bilig Türk Dünyası Sosyal Bilimler Dergisi, 25, 99-124.

Önal M. N. (2013). Muğla Efsaneleri (Araştırma-İnceleme). Muğla: Muğla Sitkı Koçman Üniversitesi Yayınları.

Soykan, F. (2006). Avrupa'da kırsal turizme bakış kazanılan deneyim. II. Balıkesir Ulusal Turizm Kongresi, ss.72-73, (20-22 Nisan). 


\section{Kaynakça Bilgisi / Citation Information}

Önal, M. N., Dalgın, T. ve Karadağ, L. (2018). Kırsal turizm bağlamında Muğla'da dağ kültü, eren kültü kapsamındaki gelenekler ve şenlikler. OPUS-Uluslararası Toplum Araştırmaları Dergisi, 9(16), 2328-2342. DOI: 10.26466/opus.486024 